\title{
A Mixed-Methods Study of Multi-Level Factors Influencing Mammography Overuse: Implications for De-implementation.
}

\section{Jessica D. Austin}

Columbia University Mailman School of Public Health https://orcid.org/0000-0001-8286-7801

\section{Parisa Tehranifar}

Columbia University Mailman School of Public Health

Carmen B. Rodriguez

Columbia University Mailman School of Public Health

\section{Laura Brotzman}

Columbia University Mailman School of Public Health

\section{Mariangela Agovino}

Columbia University Mailman School of Public Health

\section{Danya Ziazadeh}

Columbia University Mailman School of Public Health

\section{Nathalie Moise}

Columbia University Department of Medicine

Rachel C. Shelton ( $\nabla$ rs3108@cumc.columbia.edu )

Columbia University https://orcid.org/0000-0001-6496-6339

\section{Research}

Keywords: De-Implementation, Overuse, Mammography Screening, Mixed-Methods, Multi-level

Posted Date: June 28th, 2021

DOI: https://doi.org/10.21203/rs.3.rs-506568/v2

License: (c) (1) This work is licensed under a Creative Commons Attribution 4.0 International License. Read Full License 


\section{Abstract \\ Background}

There is growing concern that routine mammography screening is overused among older women. Successful and equitable de-implementation of mammography will require a multi-level understanding of the factors contributing to mammography overuse.

\section{Methods}

This explanatory, sequential, mixed-methods study collected survey data $(n=52,73.1 \%$ Hispanic, 73.1\% Spanish-speaking) from women $\geq 70$ years of age at the time of screening mammography, followed by semi-structured interviews with a subset of older women completing the survey $(n=19,63.2 \%$ Hispanic, 63.2\% Spanish-speaking) and providers ( $n=5,4$ primary care, 1 obstetrics and gynecology) to better understand multi-level factors influencing mammography overuse and inform potential deimplementation strategies. We conducted descriptive analysis of survey data and content analysis of qualitative interview data. Survey and interview data were examined separately, compared, integrated, and organized according to Norton and Chambers Continuum of Factors Influencing De-Implementation Process.

\section{Results}

Survey findings show that $87.2 \%$ of older women believe it is important to plan for an annual mammogram, $80.8 \%$ received a provider recommendation, and $78.9 \%$ received a reminder in the last 12 months to schedule a mammogram. Per interviews with older women, the majority were unaware of or did not experience overuse and intended to continue mammography screening. Findings from interviews with older women and providers suggest that there are multiple opportunities for older women to obtain a mammogram. Per provider interviews, almost all reported that overuse was not viewed as a priority by the system or other providers. Providers also discussed that variation in mammography screening practices across providers, fear of malpractice, and monetary incentives may be reasons for overuse. Providers identified potential strategies including patient and provider education around harms of screening, leveraging the electronic health record to identify women who may no longer benefit from screening, customizing system-generated reminder letters, and organizing workgroups to develop a standard process of care around mammography screening.

\section{Conclusions}

Multi-level factors contributing to mammography overuse are dynamic and reinforced. To ensure equitable de-implementation, there is a need for more refined theories, models, and frameworks for de- 
implementation with a strong patient-level component that considers the interplay between multilevel factors and the larger care delivery process.

\section{Contributions To The Literature}

- Routine mammography screening is widely implemented but offers limited health benefits while posing unnecessary health risks for older women with diminishing life expectancy and competing health risks.

- De-implementation of routine mammography screening in older women offers an excellent opportunity for advancing the science of de-implementation.

- This study provides a grounded empirical example illustrating how factors at one level (patient) can be perpetuated or reinforced by factors across multiple levels of influence (interpersonal, provider, system).

- Considering the experiences and views of populations underrepresented in de-implementation science research, as well as the larger process of care delivery is important in developing and implementing multi-level de-implementation strategies.

\section{Introduction}

In recent years, there has been growing emphasis on decreasing or "de-implementing" the delivery of unnecessary or low-value healthcare. ${ }^{1-5}$ De-implementation refers to reducing, discontinuing, or replacing healthcare that is ineffective, inappropriate, and/or unproven. This area has received growing attention among funders and healthcare systems given that it is a vital part of improving overall population health, increasing the quality of care, decreasing unnecessary costs, and minimizing patient harm. ${ }^{1}$ Several campaigns, such as 'Choosing Wisely', have focused on efforts to decrease healthcare overuse for a range of health issues (e.g. prostate cancer screening, back pain imaging, cardiac and vitamin D screening, and prescribing opioids for migraine). ${ }^{4,6}$ Overuse of care and services in the context of cancer - including overscreening, overdiagnosis, and overtreatment - is common and can cause unnecessary harm, emotional distress, and increased cost for patients and the healthcare system, ${ }^{7-9}$; however, to date, de-implementation in the context of routine mammography screening for older adults has not been thoroughly examined, and offers an excellent opportunity for advancing the science of de-implementation in clinical and healthcare contexts. ${ }^{1,2,10}$

There is growing concern that mammography screening is overused in older women, offering limited benefits while posing unnecessary health risks. ${ }^{11}$ Mammography screening is associated with a 15-25\% reduction in breast cancer mortality after $10-15$ years, ${ }^{12}$ but evidence suggests that it does not lead to a significant reduction in breast cancer mortality among women with limited life expectancies and greater competing health risks. ${ }^{13-16}$ Rather, it may pose substantial and immediate harms, such as anxiety, financial and time burden, as well as overdiagnosis and overtreatment of tumors that would not have resulted in death. ${ }^{14,17-19}$ Current professional guidelines (e.g., US Preventive Services Task Force, 
American Cancer Society, American College of Physicians) do not support routine mammography screening for women ages 75 and above, ${ }^{20-23}$ yet, $56 \%$ of women 75 years and older report a recent mammogram, half of whom have a life expectancy less than 10 years. ${ }^{24}$

While prior studies have explored factors promoting mammography utilization and adherence, factors contributing to mammography overuse among older women remains largely unknown. ${ }^{25-27} \mathrm{~A}$ recent narrative review of older women's perspectives around mammography screening found that older women are largely uninformed about cancer screening guidelines and the potential harms of mammography screening. ${ }^{28}$ Other studies also report that most healthcare providers do not discuss the uncertain balance of mammography benefits and harms, and over $70 \%$ continue to recommend mammography screening to their older patients. ${ }^{29-31}$ Further, healthcare systems may be less likely to reduce or discontinue an intervention if it generates considerable revenue. ${ }^{1}$ Thus, successful de-implementation of mammography screening in older women poses a substantial and complex challenge that requires an understanding of multi-level factors contributing to mammography overuse.

While frameworks for conceptualizing, understanding, and guiding de-implementation have been proposed, few have been applied or empirically tested to examine factors and strategies to reduce mammography overuse. ${ }^{32}$ Norton and Chambers proposed an organizing framework, Continuum of Factors Influencing De-implementation Process, for understanding de-implementation of unnecessary cancer treatments, practices, and interventions. ${ }^{2}$ The framework recognizes that factors influencing deimplementation efforts operate at multiple socioecological levels (e.g., patient's beliefs and trust, provider attitudes and self-efficacy, system-level leadership, and societal or cultural norms) and calls for multi-level strategies (e.g., techniques, approaches, tactics, or methods) that align with and address pre-identified factors within a specific context and population, with the goal of facilitating the de-implementation process. While this framework has not yet been empirically applied to understand mammography overuse, it is intended to serve as a starting point that can be refined as it is applied to different populations and settings, including historically marginalized groups.

Understanding de-implementation of routine mammography screening in older women offers the opportunity for advancing the science of de-implementation in clinical and healthcare contexts. Among the most critical next steps is ensuring that de-implementation efforts are equitable. ${ }^{33}$ To date, few studies have included the perspectives of older, racial/ethnic minority women around mammography screening. ${ }^{28}$ Understanding the perspectives and experiences of these populations is critical for ensuring de-implementation efforts do not further exacerbate existing disparities in cancer screening. ${ }^{33,34}$ To this end, the purpose of this study was to examine multi-level factors contributing to mammography screening overuse at one of the largest ambulatory care settings in New York City and to elicit potential de-implementation strategies to reduce mammography screening overuse at the patient, provider and system levels.

\section{Methods}


This explanatory-sequential mixed-methods study collected in-person survey data from older women followed by in-depth interviews with a subset of older women and providers to better understand factors influencing mammography overuse at the patient, provider, and system-levels. The survey and interview design were informed by an extensive review of the literature on prevalence, benefits, harms, attitudes and practices associated with breast cancer screening in older women, and national recommendations for mammography screening. The older women's survey was designed to provide a broad understanding of potential factors contributing to mammography overuse. The older women and provider semi-structured interview guides were designed to add depth and context to survey findings and to elicit insights into the processes and mechanisms through which routine mammography is reinforced and to inform the development of potential de-implementation strategies. The study was approved by the Columbia University Medical Center Institutional Review Board. All participants provided written and/or verbal consent at time of recruitment, survey, and interviews. Older women received separate gift cards for completing the survey and interview. Providers did not receive compensation for participation.

\section{Setting and Sample}

We recruited women over the age of 70 years presenting for screening mammography at a clinic in New York City ( 14000 mammograms/year) to complete an in-person survey. Women who expressed a willingness to participate in follow-up studies later received a mailed invitation and a phone call to take part in a semi-structured interview and were provided with the option to opt-out. We also identified primary care and obstetrics and gynecology (OBGYN) providers who predominately serve older women and are involved in recommending mammography screening from Columbia University Irving Medical Center, the same system where women were recruited. Providers were approached via email and in-person to participate in semi-structured interviews.

\section{Data Collection}

Table 1 provides a detailed summary of the study methods including the data collection source, domain assessed, and example survey and interviews items. Between January and July of 2018, a total of 52 older women were approached and completed an in-person survey (27\% in English and $73 \%$ in Spanish). The survey collected sociodemographic, clinical, and mammography screening data to assess older women's knowledge, attitudes and beliefs (motivation, perceived barriers, perceived seriousness, perceived severity) around mammography screening, screening communication, and shared decisionmaking. Between June and August 2019, two members (1 bilingual; 1 English-speaking) of the research team trained in qualitative methods completed 19 semi-structured interviews with a sub-sample of older women that completed the survey. The interview guide elicited older women's attitudes and beliefs around mammography screening, communication and shared-decision making, the process of obtaining a mammogram, and perceptions of and sources of healthcare overuse more broadly. Characteristics of the survey and interview population of older women is provided in the Supplement. Next, we conducted 5 provider semi-structured interviews (4 primary care providers; 1 OBGYN) between October 2019 and February 2020. The interview guide elicited provider's knowledge, attitudes, and beliefs towards 
mammography screening guidelines, how they decide and communicate with older women about the need for mammography screening, and the referral process. Additionally, we asked providers their perceptions of sources of mammography overuse and potential strategies to reduce overuse.

\section{Data Analysis}

Researchers trained in mixed-methods analysis performed descriptive analysis of survey data and thematic analysis of interview data focusing on factors influencing mammography overuse at the patient, provider, and system level. The survey and interview data were analyzed separately, compared, and then integrated during the data analysis phase. We analyzed and organized findings according to Norton \& Chambers framework (Continuum of Factors Influencing De-implementation Process) ${ }^{2}$ to facilitate a deeper understanding of factors contributing to mammography overuse at the patient, provider, and system levels (e.g., patient and provider attitudes and beliefs, norms, system leadership, etc.). We also grouped potential de-implementation strategies proposed in provider interviews by level of influence (e.g. patient, provider, system). Survey data is presented first, followed by qualitative interview data for older women and providers. Quantitative survey data was analyzed using SAS 9.4 and qualitative data was organized and analyzed using NVivo software.

\section{Results}

\section{Older Women Survey Findings}

Older women completing the patient survey were between the ages of 70 to 89 (mean 74.6). The majority of participants were Hispanic (71.1\%), Spanish-speaking (73.1\%), and $80.8 \%$ were born outside the US (61.5\% Dominican Republic). In addition, $75 \%$ had less than a college degree with marginal $(28.9 \%)$ or low health literacy (28.9\%). Approximately $83 \%$ reported having three or more self-reported doctor diagnosed chronic conditions and only $26.9 \%$ perceived their health to be very good or excellent. Finally, $13.5 \%$ of older women reported a family history of breast cancer and $44.2 \%$ reported ever receiving a call back for additional diagnostic tests after a routine mammogram.

Table 2 provides a summary of key survey findings. Older women have been receiving mammograms, on average, for 30.7 years (SD 8.1) and in terms of mammography frequency, $63.5 \%$ think women should receive a mammogram once a year. In addition, $68.0 \%$ of older women perceived that getting a mammogram meant that they did not have to worry about breast cancer, $71.4 \%$ believed treatment would not be as bad, and $87.8 \%$ believed that their chances of dying from breast cancer would decrease by getting a mammogram. All but one older woman reported that they 'agree' or 'strongly agree' that having a mammogram will help find breast lumps early (98.0\%). Despite $79.6 \%$ of older women reporting that they 'rarely' or 'never' worry about breast cancer, $87.2 \%$ of women 'agree' or 'strongly agree' that it is important to have an annual mammogram.

Over $80 \%$ of older women reported that their provider continues to recommend mammograms, and $86.5 \%$ indicated that they have not discussed stopping mammograms with any of their providers. Among those 
that did have a conversation with their provider to stop mammography screening $(n=7)$, the majority were Hispanic (71.4\%), foreign-born (71.4\%), reporting fair to poor health $(71.4 \%)$, and no history family history of breast cancer $(100 \%)$. Only $11.8 \%$ of older women discussed stopping mammograms with family member and/or a friend. Further, nearly $80 \%$ reported receiving a letter, a phone call, or email in the last 12 months reminding them to make an appointment for a mammogram. More generally, when making decisions about their health, $89.4 \%$ of older women 'agree' that their provider decides when they should get screened for health problems, $80 \%$ consult at least one family member when making health decisions, and $38.4 \%$ consult a friend, neighbor, or caregiver.

\section{Older Women Interview Findings}

We conducted semi-structured interviews with a subset of older women who completed the survey to elicit their attitudes and beliefs towards mammography screening to provide depth and context to survey findings. There were no significant differences in sample characteristics between the interview or survey population (see Supplement). Interview findings are presented by key themes: 1) Older women intend to and are encouraged to receive an annual mammogram;2) There are many opportunities for older women to obtain a mammogram; and 3) Older women are unaware of or have not experienced overuse.

\section{Older women intend to and are encouraged to receive an annual mammogram.}

We found that the majority of older women believed that getting a yearly mammogram was important to stay health and for detecting and treating breast cancer at an early stage. These beliefs were often shaped or encouraged by personal experiences with mammography screening (e.g., receiving a call to return for additional diagnostic tests), receiving a provider recommendation or reminder letter, and/or by knowing someone diagnosed with or dying from breast cancer. In turn, many women said that they intended on continuing mammograph screening. As a 71-year-old, Hispanic woman summarized:

"I'm very protective of my appointments and my specialists, because one never knows, by avoiding medical attention, when one can develop a problem that you wouldn't even know about, or feel symptoms for, and it could be serious. So I'm very protective of my appointments, I get my mammogram every year."

\section{There are many opportunities to obtain a mammogram.}

We asked older women to describe the process of how they came to get a mammogram. In most cases, women said that their provider would recommend and/or refer them to get a yearly mammogram. Several women also stated that they received a reminder letter or a phone call reminding them to get a yearly mammogram. This reminder would sometimes prompt them to call their provider's office for a referral or call the mammography screening clinic directly to obtain an appointment. A few women also stated that the letters served as a personal reminder to discuss mammography screening with their providers at their yearly appointment. As a 72-year-old, Hispanic woman described:

"Well, my primary care doctor reminds me and they also send me the reminder, and if they don't remind me, I see in the paper [letter] I have that it's time to get it.[6.12.19 EN]" 


\section{Older women are unaware of or have not experienced overuse}

We described the concept of overuse/unnecessary to gather information on older women's understanding and opinions/views about healthcare overuse. We asked women if they ever heard of or experienced 'unnecessary' or 'excessive healthcare', herein referred to as overuse, and if they ever received excessive or unnecessary care. The majority of participants had not heard of or experienced healthcare overuse and many reinforced the importance and necessity of routine medical care, including mammograms, for detecting illness. As a 71-year-old, Hispanic older woman reported:

"I think the doctor tells you the care you need, at the moment you need it ... I don't think it's excessive, because, if you are going to have a mammogram, and the mammogram does not work out well, he'll refer you to the professional"

We also asked women reasons for overuse more broadly and specific to mammography screening. The majority of women reiterated that all care is important but several report that providers may give care that is not necessary if it is covered by insurance. Older women also identified a number of other potential reasons for healthcare overuse including patient requests for unnecessary care, patient non-adherence, perceptions that more care is better, provider fear of missing a diagnosis, and healthcare system fragmentation. As one 78-year-old, Hispanic woman described:

"There are people who think that it's [overuse/unnecessary or excessive care] to collect insurance, either insurance, or for the person, that's the reason they do it. I think that maybe they [providers] also care about the patient, don't they?"

\section{Provider Qualitative Interviews}

We asked providers which guideline recommendations they followed when recommending for or against screening, how they discussed mammography screening with older patients, and about their perceptions around overscreening or overuse of mammography. We identified three major themes: 1) Challenges adhering to guideline recommendations for mammography screening among older women, 2) Lack of a standardized process or approach to mammography screening for older women, and 3) Provider-reported strategies to reduce mammography overuse.

\section{Challenges adhering to guideline recommendations.}

All providers stated that they followed the guideline recommendations for mammography screening released by their respective professional organizations, mainly the USPSTF and American College of OBGYN. However, providers discussed that providers within their own specialty and/or clinic did not always adhere to these guidelines. As one primary care provider described, "I've been here a long time I've learned that certain providers are very set in their ways and don't want intervention." In addition, providers (2 primary care and $1 \mathrm{OBGYN}$ ) described that other providers believe that the benefits of screening outweigh the potential harms of not screening. As one primary care provider reported: 
"I kind of believe two physicians who basically screen annually until death... So if we have a pretty decent detection test and breast biopsy is a relatively benign procedure, not super morbid, why not just do it?"

Providers perceived that their colleague's decision to continue screening indefinitely may be due to fear of malpractice, past experiences/changing guidelines, and to avoid confusion among older women. According to one primary care provider:

"I mean god forbid you tried to convince them to be screened bi-yearly and then they have something on their mammogram and they didn't get it yearly, like the hospital recommended. You know, like if that ever happened the doctor would be in a terrible position, even though that's what the guidelines say."

\section{Lack of a standardized process or approach to mammography screening.}

Providers stated that there is no within system consensus on how to approach screening within this age group. All providers stated that older women receive a letter from outside their clinic reminding older women to get an annual mammogram but it was unclear if the letter came from radiology or the mammography screening clinic. Primary care providers also described how this letter created conflict and confusion around which provider specialty is in charge of mammography screening and made it difficult for them to discuss stopping or reducing screening during an in-person appointment. As one primary care provider described:

"I think that this is a really difficult area because even though I feel pretty confident in the guidelines and the data that mammograms should be every two years, our patients get a letter reminding them that they should have their yearly mammogram. I think that that creates a lot of confusion."

In addition, a few providers described how it is challenging to know which women are less likely to benefit from mammography screening and that they did not feel comfortable discussing the pertinence of limited life-expectancy for screening with their patients. As one OBGYN provider stated:

"That's really a horrible message to give to people that, "Oh you're going to die soon so you really don't need that." And so if women want to have the imaging then I think that they should and we don't have the information on older people except to say when people get breast cancer when they're older it usually grows a little bit slow."

Several providers also reported that an in-person visit was not required for older women to obtain a referral for a mammogram and that older women could call the provider's office and speak with a nurse who can generate an order or have the referral signed off by another provider who is unfamiliar with the patient's history. As one primary care provider described:

"Now the annual mammogram [letter] that I learn tell people that they are overdue for their mammogram and my patients either will go around me to schedule which they can do or they will alternatively bring me the letters from radiology and say, "This says I'm overdue," and that's the whole of the conversation that fairly prompts me to say the same things that I've said." 
Finally, providers described how mammography overuse is not perceived to be a priority by system leadership, administrators, or other providers. Two providers said that mammography screening is seen as important for revenue generation at the system level. As one primary care provider described:

"...then this issue of screening every year, I think unless there's institutional support for the doctors who want to screen every other year it's really hard to be put in that position... it's hard because there's also a conflict of interest because it's a moneymaker for Radiology."

\section{Provider-reported strategies to reduce mammography overuse.}

We elicited ideas about potential de-implementation strategies by asking providers how providers and systems could better support older women in being adherent to mammography screening guidelines. Several providers stated that older women and providers could receive educational resources about the harms and limited benefits of mammography screening to help facilitate informed discussions around screening. A couple of providers also suggested utilizing the electronic health record to identify older women for whom reducing the frequency of or stopping mammography screening are recommended (e.g., women with < 10-year life expectancy) and to customize system-generated reminder letters based on individual breast cancer risk and health status (i.e., family or personal history of breast cancer; comorbidities). Per two primary care providers:

"There's a couple of pretty decent decisions aids out there for breast cancer screening... Having that integrated in to the EMR in a meaningful way that could be very useful."

"I wonder if when you put in the order there was sort of a drop down or a view that you do a patients risk score or a drop-down screening tool... with guidelines that the hospital feels are the guidelines that we should follow."

Finally, a couple of providers emphasized the need for a workgroup comprised of key stakeholders (e.g., primary care providers, OBGYN, radiology, system leadership, administrators) to educate about the harms of mammography overuse; additionally, they could develop a standard process of care around mammography screening that delineates providers roles in the referral process and supports a single set of guidelines, to help reduce variation in screening practices and provider recommendations regarding mammography. As one primary care provider summarizes:

"what needs to be done in coordination with really a population health perspective on what our given practices are doing about screening more broadly as opposed to us being alone. That will require someone in a leadership level wanting to think about the re-organizing screening tests in some sort of way and think about resources and is there any quality metrics, is there any incentive, how the incentives aligned for that type of a process. So I think that process involves other practices then it makes sense that radiology would be included in that conversation so that we can align similar policies if that was possible."

\section{Multi-level Factors and Potential De-Implementation Strategies for Mammography Overuse}


In Table 3, we combined and triangulated quantitative and qualitative data from all sources and organized data according to Norton \& Chambers framework ${ }^{2}$ to identify factors at the patient, provider, and system-level contributing to mammography overuse. We also grouped and matched potential deimplementation strategies proposed in provider interviews by level of influence. For example, analysis of all data sources suggested that older women are unaware of the potential harms of overuse and have strong intentions to continue mammography. A primary care provider recommended implementing a decision aid to educate women about the potential harms of screening and recommended that the decision aid be integrated into the electronic health record to help facilitate discussions.

It is important to note that some of the de-implementation strategies identified by providers span multiple levels, such as education about the harms of overscreening (patient and provider) and integrating educational/training tools into the electronic health record (provider and systems). Moreover, many of the factors contributing to overuse at one level were reinforced or facilitated by factors identified at another level. For instance, system-generated reminder letters reinforced older women's beliefs and mammography screening behavior and also created challenges for providers discussing the option to reduce or stop screening with their patients.

\section{Discussion}

This is one of the first empirical studies to use a mixed-methods approach to understand the factors, processes, and potential strategies at multiple levels that influence mammography overuse in older women. Overall, we found that mammography overuse is not perceived as a priority in our setting and that factors driving overuse are complex and often reinforced through a dynamic interplay of factors across multiple levels of the socioecological model. Specifically, we found that the characteristics and attributes of older women (e.g. lack of knowledge of the harms, positive attitudes and intentions towards screening), providers (e.g., discomfort discussing screening cessation, fear of malpractice, views on how best to approach screening), and the healthcare system (e.g., variation in how women obtain a mammogram, incentives) all contribute to and reinforce mammography overuse. This study also provides valuable insights into potential de-implementation strategies that span multiple levels in our setting; however, more research is needed to understand how these strategies fit the unique needs and context of our patient population, providers, and healthcare system.

Findings from this study support that de-implementation is likely more challenging than implementation because it works against prevailing practices and beliefs that reinforce the importance of mammography screening. ${ }^{1,37}$ Similar to other studies, older women in our sample hold strong intentions to continue annual mammography screening. ${ }^{28,38,39}$ Intention has shown to be a strong predictor of mammography screening cessation ${ }^{40}$ and should be examined in light of factors that act as barriers and facilitators of mammography screening. ${ }^{41}$ In our study, insights from qualitative interviews with older women suggest that screening intention is reinforced by multiple factors, such as having a direct connection to breast cancer (i.e., family history or knowing someone close to their age with breast cancer), receiving a provider recommendation/referral, and a system-generated letter reminder for annual screening. In addition, 
findings from provider interviews add to the existing literature that primary care providers may be reluctant to discuss reducing mammography screening for older women out of fear of medical malpractice, discomfort discussing sensitive topics, and to avoid confusion from conflicting recommendations around screening. ${ }^{42-44}$ We found that this reluctance may be further reinforced by older women's positive views around screening, a lack of institutional leadership and guidance on how to approach mammography screening from a system-level, and financial incentives to continue mammography screening. To this end, greater recognition should be given to the complex interplay between multilevel factors contributing to mammography overuse in older women.

It is well documented that system-level factors or characteristics including practice size, type, resources, staffing, organizational culture, and cost influence cancer screening but less attention has focused on the care delivery process. ${ }^{1,41}$ Our findings suggest that there is no standardized process or approach to mammography screening in our setting resulting in variation in mammography screening practices (i.e., referrals, scheduling appointment, guideline implementation) across providers and increased opportunities for older women to obtain a mammogram. While some practice variation may be justified when based on older women's health and preferences, as our findings support, variation resulting from conflicting guideline recommendations ${ }^{45}$, lack of care continuity ${ }^{46}$, lack of communication ${ }^{47}$ or teamwork ${ }^{48}$ between providers can contribute to healthcare overuse. ${ }^{1,41,49}$ De-implementation science frameworks acknowledge the need to examine practice variation and the overall care delivery process early on in the process of identifying and prioritizing low-value practices. ${ }^{50}$ However, few acknowledge practice variation or the larger care delivery process as a factor or determinant contributing to overuse, despite studies linking the care delivery process to overuse. ${ }^{41}$ Particularly for long-standing and embedded practices, such as mammography screening, more empirical work in this area is needed to better understand the role of the care delivery process early on in the de-implementation process, as well as a determinant of overuse to inform the development of system-level strategies to reduce variation.

A unique feature of our study is that a large proportion of our sample of older women identified as Hispanic (73.1\% survey, 63.2\% interview), Spanish-speaking (73.1\% survey, 63.2\% interview), believed it was important to plan to have a yearly mammogram ( $87.2 \%$ survey, $88.9 \%$ interview), and all received a mammogram in the last 12 months. These findings support the broader notion that racial/ethnic minority populations, including Hispanics, are also susceptible to overuse that is perpetuated by providers and the operations of the system. ${ }^{32,34,51}$ To date, few studies on de-implementation capture the perspectives and experiences of Hispanic populations or of older women more broadly. ${ }^{28}$ In fact, a recent scoping review of de-implementation science theories, models, and frameworks found only two that account for the role of patients. ${ }^{32}$ Similar to prior studies, findings from qualitative interviews with older women found that the majority had not heard of or experienced excessive or unnecessary care and struggled to understand how receiving a mammogram could lead to harm. ${ }^{52,53}$ This perception combined with societal norms related to successful population-level efforts to address mammography underuse and limited training or preparation of providers to address overuse, may further impede de-implementation. ${ }^{54-56}$ These findings support the need for future research to understand the magnitude of and perspectives towards 
mammography overuse across diverse settings and populations, with the ultimate goal of helping to advance the science of achieving health equity through de-implementation.

There is growing recognition that strategies for de-implementation likely differ from strategies used for implementation ${ }^{32}$, but there is little evidence to indicate what these specific strategies may be and how to best develop them. This study provides a glimpse into potential strategies specific to de-implementation; given our sample size, future research is needed to further understand what strategies providers perceive to be feasible and acceptable and to develop/test the effectiveness of such strategies. As seen in our study, strategies including stakeholder engagement and leadership buy-in are likely effective for both implementation and de-implementation. ${ }^{1}$ In addition, strategies that target habit formation and disruption by changing environmental cues (e.g., leveraging the electronic health record to identify women most likely to benefit from screening, tailoring system-generated letters accordingly) and behavior (e.g., having the primary care provider review and sign off on all mammography referrals for their patients), may help to reduce variation in the mammography screening processes. ${ }^{57,58}$ Our findings also support the need for strategies that target professional biases to foster de-implementation, such as ensuring that system-level workgroups include experts from different provider specialties; emphasizing evidence and guidelines over individual clinical judgement; and encouraging providers to consider how their experiences bias their interpretations of clinical evidence. ${ }^{59}$ Importantly, de-implementation strategies should be designed and refined with health equity in mind by considering racially and ethnically diverse older women's experiences and perceptions of overuse and should reflect their cultural or communication preferences, or specific structural barriers faced. ${ }^{34,51}$

Our study has several important strengths, including the use of a mixed-methods design to facilitate a deeper understanding of factors and potential mechanisms influencing mammography overuse and inform potential de-implementation strategies. However, important limitations should be considered when interpreting results. First, the survey and interview design were not informed by theories, models, or frameworks specific to de-implementation, but instead sought to broadly understand multi-level factors contributing to mammography overuse in our setting. However, our findings provide insight into potential gaps in current conceptualizations of de-implementation of mammography overuse and we utilized the Continuum of Factors Influencing De-implementation Process ${ }^{2}$ framework to help organize our results. Second, findings from provider interviews may not represent the entire spectrum of experiences or perspectives around mammography overuse due to small sample size. Provider interviews were also limited to primary care and OBGYN providers and did not include the perspectives of other specialties, such as radiology, or system leadership who also contribute to mammography overuse. A notable strength of our study is the inclusion of older, predominately Hispanic, Spanish-speaking women who may be susceptible to underuse and overuse of mammography screening. However, our findings do include perspectives from women less than 75 years of age for which mammography screening is appropriate. Finally, all participants were recruited from a single healthcare system, limiting our ability to generalize to other settings. However, the overall synthesis of results provides important information to 
help advance the science of de-implementation by informing context-specific strategies and hypothesisgenerating directions for future research.

\section{Conclusion}

This study aligns with calls to advance the science of de-implementation and includes the experiences and perspectives of older women underrepresented in research to date. Our study emphasizes the need for further refinement and empirical testing of de-implementation theories, models, and frameworks that incorporate a strong patient-level component and considers the complex interplay between multi-level factors within the larger process of care delivery. In addition, findings from provider interviews suggest potential de-implementation strategies to reduce mammography overuse that are context-specific, spanning multiple levels, and informed by health behavior and organizational theory, as well as, theories of habit formation and disruption. Finally, these findings point to the need for more robust mixed-methods studies aimed at understanding the magnitude of mammography overuse and multi-level factors influencing mammography screening across diverse populations and settings to aid in the development and testing of strategies tailored to context and needs of the population.

\section{Declarations}

Ethical approval and consent to participate: This paper was approved by the Columbia Mailman School of Public Health Institutional Review Board. All participants provided written and/or verbal consent.

Consent for publication: Not applicable.

Disclosure of potential conflicts of interest: All authors declare no conflicts of interest.

Availability of data and materials: All data generated or analyzed during this study are available from the corresponding author on reasonable request.

Funding: Not applicable

Author Contributions: JA analyzed and interpreted survey and interview data. CR and MA analyzed survey data and performed interviews. LB performed provider interviews and analyzed older women interview data. DZ analyzed provider interview data. RS, PT, and NM developed the protocol and science. All authors read and approved the final manuscript.

\section{References}

1. Norton WE, Chambers DA. Unpacking the complexities of de-implementing inappropriate health interventions. Implementation Science. 2020;15(1):2.

2. Norton WE, Chambers DA, Kramer BS. Conceptualizing De-Implementation in Cancer Care Delivery. J Clin Oncol. 2019;37(2):93-6. 
3. Norton WE, Kennedy AE, Chambers DA. Studying de-implementation in health: an analysis of funded research grants. Implement Sci. 2017;12(1):144.

4. Cassel CK, Guest JA. Choosing wisely: helping physicians and patients make smart decisions about their care. Jama. 2012;307(17):1801-2.

5. Morgan DJ, Brownlee S, Leppin AL, et al. Setting a research agenda for medical overuse. BMJ: British Medical Journal. 2015;351:h4534.

6. Burton C, Williams L, Bucknall T, et al. Understanding how and why de-implementation works in health and care: research protocol for a realist synthesis of evidence. Systematic Reviews. 2019;8(1):194.

7. Baxi SS, Kale M, Keyhani S, et al. Overuse of Health Care Services in the Management of Cancer: A Systematic Review. Med Care. 2017;55(7):723-33.

8. Chassin MR, Galvin RW. The urgent need to improve health care quality. Institute of Medicine National Roundtable on Health Care Quality. Jama. 1998;280(11):1000-5.

9. Hicks LK. Reframing Overuse in Health Care: Time to Focus on the Harms. Journal of Oncology Practice. 2015;11(3):168-70.

10. Korenstein D, Falk R, Howell EA, Bishop T, Keyhani S. Overuse of health care services in the United States: an understudied problem. Arch Intern Med. 2012;172(2):171-8.

11. Schonberg MA. Overutilization of Breast Cancer Screening in the US: Awareness of a Growing Problem. J Gen Intern Med. 2018;33(3):238-40.

12. Walter LC, Schonberg MA. Screening mammography in older women: a review. Jama. 2014;311(13):1336-47.

13. Diab SG, Elledge RM, Clark GM. Tumor characteristics and clinical outcome of elderly women with breast cancer. J Natl Cancer Inst. 2000;92(7):550-6.

14. Walter LC, Covinsky KE. Cancer screening in elderly patients: a framework for individualized decision making. JAMA. 2001;285(21):2750-6.

15. Fletcher SW, Elmore JG. Clinical practice. Mammographic screening for breast cancer. N Engl J Med. 2003;348(17):1672-80.

16. Lee SJ, Boscardin WJ, Stijacic-Cenzer I, Conell-Price J, O'Brien S, Walter LC. Time lag to benefit after screening for breast and colorectal cancer: meta-analysis of survival data from the United States, Sweden, United Kingdom, and Denmark. BMJ. 2013;346:e8441.

17. Schonberg MA, Marcantonio ER, Li D, Silliman RA, Ngo L, McCarthy EP. Breast cancer among the oldest old: tumor characteristics, treatment choices, and survival. J Clin Oncol. 2010;28(12):203845 .

18. Schonberg MA, Silliman RA, Marcantonio ER. Weighing the benefits and burdens of mammography screening among women age 80 years or older. J Clin Oncol. 2009;27(11):1774-80.

19. Audisio RA. The surgical risk of elderly patients with cancer. Surg Oncol. 2004;13(4):169-73. 
20. Qaseem A, Lin JS, Mustafa RA, Horwitch CA, Wilt TJ. Clinical Guidelines Committee of the American College of P. Screening for Breast Cancer in Average-Risk Women: A Guidance Statement From the American College of Physicians. Ann Intern Med. 2019;170(8):547-60.

21. Siu AL, Force USPST. Screening for Breast Cancer: U.S. Preventive Services Task Force Recommendation Statement. Ann Intern Med. 2016;164(4):279-96.

22. Oeffinger KC, Fontham ET, Etzioni R, et al. Breast Cancer Screening for Women at Average Risk: 2015 Guideline Update From the American Cancer Society. JAMA. 2015;314(15):1599-614.

23. Committee on Practice B-G. Practice Bulletin Number 179: Breast Cancer Risk Assessment and Screening in Average-Risk Women. Obstet Gynecol. 2017;130(1):e1-16.

24. Schonberg MA, Breslau ES, McCarthy EP. Targeting of mammography screening according to life expectancy in women aged 75 and older. J Am Geriatr Soc. 2013;61(3):388-95.

25. Myers ER, Moorman P, Gierisch JM, et al. Benefits and Harms of Breast Cancer Screening: A Systematic Review. JAMA. 2015;314(15):1615-34.

26. Braithwaite D, Demb J, Henderson LM. Optimal breast cancer screening strategies for older women: current perspectives. Clinical interventions in aging. 2016;11:111-25.

27. Braithwaite D, Walter LC, Izano M, Kerlikowske K. Benefits and Harms of Screening Mammography by Comorbidity and Age: A Qualitative Synthesis of Observational Studies and Decision Analyses. J Gen Intern Med. 2016;31(5):561-72.

28. Austin JD, Shelton RC, Lee Argov EJ, Tehranifar P. Older Women's Perspectives Driving Mammography Screening Use and Overuse: a Narrative Review of Mixed-Methods Studies. Current Epidemiology Reports. 2020.

29. Schonberg MA, Ramanan RA, McCarthy EP, Marcantonio ER. Decision making and counseling around mammography screening for women aged 80 or older. J Gen Intern Med. 2006;21(9):979-85.

30. Hoffman RM, Lewis CL, Pignone MP, et al. Decision-making processes for breast, colorectal, and prostate cancer screening: the DECISIONS survey. Med Decis Making. 2010;30(5 Suppl):53S-64S.

31. Brotzman L, Shelton RC, Agovino M, Rodriguez CB, Moise N, Tehranifar P. Older Women's views and experiences of mammography screening in relation to aging, health status and healthcare overuse. American Society for Preventive Oncology Annual Meeting; 2020; Tucson, AZ.

32. Nilsen $P$, Ingvarsson $S$, Hasson $H$, von Thiele Schwarz U, Augustsson H. Theories, models, and frameworks for de-implementation of low-value care: A scoping review of the literature. Implementation Research Practice. 2020;1:2633489520953762.

33. Baumann AA, Cabassa LJ. Reframing implementation science to address inequities in healthcare delivery. BMC Health Serv Res. 2020;20(1):190.

34. Helfrich CD, Hartmann CW, Parikh TJ, Au DH. Promoting Health Equity through De-Implementation Research. Ethn Dis. 2019;29(Suppl 1):93-6.

35. SAS. Base SAS 9.4 procedures guide. SAS Institute; 2015.

36. NVivo qualitative data analysis software [computer program]. Version 112015. 
37. Norton WE, McCaskill-Stevens W, Chambers DA, Stella PJ, Brawley OW, Kramer BS. Delmplementing Ineffective and Low-Value Clinical Practices: Research and Practice Opportunities in Community Oncology Settings. JNCI Cancer Spectrum. 2021;5(2).

38. Schonberg MA, McCarthy EP, York M, Davis RB, Marcantonio ER. Factors influencing elderly women's mammography screening decisions: implications for counseling. BMC Geriatr. 2007;7:26.

39. Gross CP, Fried TR, Tinetti ME, et al. Decision-making and cancer screening: A qualitative study of older adults with multiple chronic conditions. Journal of Geriatric Oncology. 2015;6(2):93-100.

40. Schoenborn NL, Pinheiro A, Kistler CE, Schonberg MA. Association between Breast Cancer Screening Intention and Behavior in the Context of Screening Cessation in Older Women. Medical decision making: an international journal of the Society for Medical Decision Making. 2021;41(2):240-4.

41. Augustsson $\mathrm{H}$, Ingvarsson $\mathrm{S}$, Nilsen $\mathrm{P}$, et al. Determinants for the use and de-implementation of lowvalue care in health care: a scoping review. Implement Sci Commun. 2021;2(1):13-3.

42. Zikmund-Fisher BJ, Kullgren JT, Fagerlin A, Klamerus ML, Bernstein SJ, Kerr EA. Perceived Barriers to Implementing Individual Choosing Wisely $\left({ }^{\circledR}\right)$ Recommendations in Two National Surveys of Primary Care Providers. Journal of general internal medicine. 2017;32(2):210-7.

43. Pollack CE, Platz EA, Bhavsar NA, et al. Primary care providers' perspectives on discontinuing prostate cancer screening. Cancer. 2012;118(22):5518-24.

44. Schoenborn NL, Bowman TL 2nd, Cayea D, Pollack CE, Feeser S, Boyd C. Primary Care Practitioners' Views on Incorporating Long-term Prognosis in the Care of Older Adults. JAMA Intern Med. 2016;176(5):671-8.

45. Sharma R, Pannikottu J, Xu Y, et al. Factors Influencing Overuse of Breast Cancer Screening: A Systematic Review. Journal of Women's Health. 2018;27(9):1142-51.

46. Romano MJ, Segal JB, Pollack CE. The Association Between Continuity of Care and the Overuse of Medical Procedures. JAMA internal medicine. 2015;175(7):1148-54.

47. Redwood R, Knobloch MJ, Pellegrini DC, Ziegler MJ, Pulia M, Safdar N. Reducing unnecessary culturing: a systems approach to evaluating urine culture ordering and collection practices among nurses in two acute care settings. Antimicrob Resist Infect Control. 2018;7:4.

48. Sawan M, Jeon YH, Fois RA, Chen TF. Exploring the link between organizational climate and the use of psychotropic medicines in nursing homes: A qualitative study. Res Social Adm Pharm. 2017;13(3):513-23.

49. Brownlee S, Chalkidou K, Doust J, et al. Evidence for overuse of medical services around the world. Lancet. 2017;390(10090):156-68.

50. Niven DJ, Mrklas KJ, Holodinsky JK, et al. Towards understanding the de-adoption of low-value clinical practices: a scoping review. BMC Med. 2015;13:255.

51. Kressin NR, Lin M-Y. Race/ethnicity, and Americans' perceptions and experiences of over- and underuse of care: a cross-sectional study. BMC Health Serv Res. 2015;15:443-3. 
52. Schleifer D, Rothman DJ. "The ultimate decision is yours": exploring patients' attitudes about the overuse of medical interventions. PLoS One. 2012;7(12):e52552-2.

53. Pappadis MR, Volk RJ, Krishnan S, et al. Perceptions of overdetection of breast cancer among women 70 years of age and older in the USA: a mixed-methods analysis. BMJ open. 2018;8(6):e022138.

54. Torke AM, Schwartz PH, Holtz LR, Montz K, Sachs GA. Older Adults and Forgoing Cancer Screening: "I Think It Would Be Strange". JAMA Internal Medicine. 2013;173(7):526-31.

55. Ellen ME, Wilson MG, Vélez M, et al. Addressing overuse of health services in health systems: a critical interpretive synthesis. Health Research Policy Systems. 2018;16(1):48.

56. Levinson W, Kallewaard M, Bhatia RS, Wolfson D, Shortt S, Kerr EA. 'Choosing Wisely': a growing international campaign. BMJ Qual Saf. 2015;24(2):167-74.

57. Wood W. Habit in Personality and Social Psychology. Pers Soc Psychol Rev. 2017;21(4):389-403.

58. Helfrich CD, Rose AJ, Hartmann CW, et al. How the dual process model of human cognition can inform efforts to de-implement ineffective and harmful clinical practices: A preliminary model of unlearning and substitution. J Eval Clin Pract. 2018;24(1):198-205.

59. Creating Value In Health By Understanding And Overcoming Resistance To De-Innovation. Health Affairs. 2015;34(2):239-44.

\section{Tables}


Table 1. Summary of Data Collection Methods and Domains

\begin{tabular}{|c|c|c|}
\hline Domain & \begin{tabular}{|l|} 
Data \\
Source \\
\end{tabular} & Ex. Item(s) \\
\hline \multirow{2}{*}{$\begin{array}{l}\text { Knowledge of } \\
\text { Mammography } \\
\text { Screening Guidelines }\end{array}$} & $\begin{array}{l}\text { Patient } \\
\text { Surveys }\end{array}$ & How often do you think you need to get a mammogram? \\
\hline & $\begin{array}{l}\text { Provider } \\
\text { Interview }\end{array}$ & $\begin{array}{l}\text { What guidelines or clinical recommendations do you follow when } \\
\text { recommending for or against mammography screening? }\end{array}$ \\
\hline \multirow[t]{3}{*}{$\begin{array}{l}\text { Attitudes/Beliefs } \\
\text { towards } \\
\text { Mammography } \\
\text { Screening }\end{array}$} & $\begin{array}{l}\text { Patient } \\
\text { Survey }\end{array}$ & $\begin{array}{l}\text { If I get a mammogram and nothing is found, I do not worry as much } \\
\text { about breast cancer. } \\
\text { It is important for me to plan to have a yearly mammogram. }\end{array}$ \\
\hline & $\begin{array}{l}\text { Patient } \\
\text { Interview }\end{array}$ & $\begin{array}{l}\text { Can you tell me why you get mammograms? } \\
\text { In general, how would you describe your experiences of getting } \\
\text { mammograms? }\end{array}$ \\
\hline & $\begin{array}{l}\text { Provider } \\
\text { Interview }\end{array}$ & $\begin{array}{l}\text { What are your perceptions of the utility of (breast cancer screening) } \\
\text { guidelines in clinical practice? } \\
\text { How do you feel about recommending mammography screening for } \\
\text { women in their 70s? 80s? }\end{array}$ \\
\hline \multirow{2}{*}{$\begin{array}{l}\text { Communication } \\
\text { around } \\
\text { Mammography } \\
\text { Screening }\end{array}$} & $\begin{array}{l}\text { Patient } \\
\text { Survey }\end{array}$ & $\begin{array}{l}\text { Have you ever had a conversation with a doctor/family/friend about } \\
\text { whether you should stop screening mammography? }\end{array}$ \\
\hline & $\begin{array}{l}\text { Provider } \\
\text { Interview } \\
\end{array}$ & $\begin{array}{l}\text { Tell me about how/whether you discuss mammogram screening with } \\
\text { your patients? }\end{array}$ \\
\hline \multirow[t]{3}{*}{$\begin{array}{l}\text { Shared decision- } \\
\text { making }\end{array}$} & $\begin{array}{l}\text { Patient } \\
\text { Survey }\end{array}$ & $\begin{array}{l}\text { When you have to make a decision about your health, how often do you } \\
\text { consult family, friends, neighbors, or caregivers? } \\
\text { Please tell us if you strongly agree, agree, disagree, or strongly disagree } \\
\text { to the following statements. My doctor/family members decide when I } \\
\text { should be screened for health problems. }\end{array}$ \\
\hline & $\begin{array}{l}\text { Patient } \\
\text { Interviews } \\
\end{array}$ & How do you make the decision to get a mammogram? \\
\hline & \begin{tabular}{|l|} 
Provider \\
Interviews \\
\end{tabular} & $\begin{array}{l}\text { What factors influence whether you discuss/refer for mammography } \\
\text { screening among your patients? }\end{array}$ \\
\hline \multirow[t]{3}{*}{$\begin{array}{l}\text { Mammography } \\
\text { Screening Process }\end{array}$} & $\begin{array}{l}\text { Patient } \\
\text { Survey }\end{array}$ & $\begin{array}{l}\text { Within the past } 12 \text { months, has a doctor or other healthcare provider } \\
\text { recommended that you have a mammogram? } \\
\text { Within the past } 12 \text { months, have you received a letter, phone call or } \\
\text { email reminding you to make an appointment for a mammogram? }\end{array}$ \\
\hline & \begin{tabular}{|l|} 
Patient \\
Interviews \\
\end{tabular} & $\begin{array}{l}\text { Can you take me through the process of how you came to get your } \\
\text { mammogram? }\end{array}$ \\
\hline & $\begin{array}{l}\text { Provider } \\
\text { Interviews }\end{array}$ & $\begin{array}{l}\text { Tell me about the process you use for referring/recommending patients } \\
\text { for mammograms either in the patient/provider appointment or at } \\
\text { system level (e.g. in-person, letter, other)? }\end{array}$ \\
\hline $\begin{array}{l}\text { Healthcare/Screening } \\
\text { Overuse }\end{array}$ & $\begin{array}{l}\text { Patient } \\
\text { Interviews }\end{array}$ & $\begin{array}{l}\text { Have you ever heard or thought about the issue of getting too much } \\
\text { healthcare? Please tell me about your thoughts. } \\
\text { In your opinion, what are some of the reasons or motivations for doctors } \\
\text { to order too many screening tests or medical services? Are there other }\end{array}$ \\
\hline
\end{tabular}




\begin{tabular}{|l|l|l} 
& & $\begin{array}{l}\text { reasons that you think contribute to patients receiving too much } \\
\text { screening or medical services? }\end{array}$ \\
\cline { 2 - 3 } & $\begin{array}{l}\text { Provider } \\
\text { Interviews }\end{array}$ & $\begin{array}{l}\text { What are your perceptions of potential over-screening or over-use of } \\
\text { mammography among certain groups? }\end{array}$ \\
\hline $\begin{array}{l}\text { Potential De- } \\
\text { Implementation } \\
\text { Strategies }\end{array}$ & Provider & What are ways that providers or systems could better support patients in \\
Interviews & being adherent to mammography screening guidelines? \\
\hline
\end{tabular}

Table 2. Survey Items on Older Women's' Perspectives around Mammography Screening and DecisionMaking $(n=52)$

\begin{tabular}{|c|c|}
\hline & n (\%) \\
\hline $\begin{array}{r}\text { Perceived mammogram frequency } \\
\text { Once a year } \\
\text { Every two years } \\
\text { Every three years/as } \\
\text { needed/other }\end{array}$ & $\begin{array}{l}33(63.5) \\
6(11.5) \\
13(25.0)\end{array}$ \\
\hline Years of screening (mean, SD) & $30.7(8.1)$ \\
\hline $\begin{array}{l}\text { If I get a mammogram and nothing } \\
\text { is found, I do not worry as much } \\
\text { about breast cancer. } \\
\text { Agree or Strongly agree } \\
\text { Disagree or Strongly disagree }\end{array}$ & $\begin{array}{l}34(68.0) \\
16(32.0)\end{array}$ \\
\hline $\begin{array}{l}\text { Having a mammogram will help me } \\
\text { find breast lumps early. } \\
\text { Agree or Strongly agree } \\
\text { Disagree or Strongly disagree }\end{array}$ & $\begin{array}{l}49(98.0) \\
1(2.0)\end{array}$ \\
\hline $\begin{array}{l}\text { If I find a lump through a } \\
\text { mammogram, my treatment for } \\
\text { breast cancer may not be as bad. } \\
\text { Agree or Strongly agree } \\
\text { Disagree or Strongly disagree }\end{array}$ & $\begin{array}{l}35(71.4) \\
14(28.6)\end{array}$ \\
\hline $\begin{array}{l}\text { Having a mammogram will } \\
\text { decrease my chances of dying from } \\
\text { breast cancer. } \\
\text { Agree or Strongly agree } \\
\text { Disagree or Strongly disagree }\end{array}$ & $\begin{array}{l}43(87.8) \\
6(12.2)\end{array}$ \\
\hline $\begin{array}{r}\text { Worry about breast cancer } \\
\text { Rarely or never } \\
\text { Sometimes } \\
\text { Often/All the time }\end{array}$ & $\begin{array}{l}39(79.6) \\
7(14.3) \\
3(6.1)\end{array}$ \\
\hline $\begin{array}{l}\text { Perceived breast cancer } \\
\text { seriousness }\end{array}$ & $8.5(2.3)$ \\
\hline $\begin{array}{l}\text { Important to have a yearly } \\
\text { mammogram. } \\
\text { Agree or Strongly agree } \\
\text { Disagree or Strongly disagree }\end{array}$ & $\begin{array}{l}41(87.2) \\
6(12.8)\end{array}$ \\
\hline $\begin{array}{l}\text { Provider recommended } \\
\text { mammogram }\end{array}$ & $\begin{array}{l}42(80.8) \\
9(5.8)\end{array}$ \\
\hline
\end{tabular}




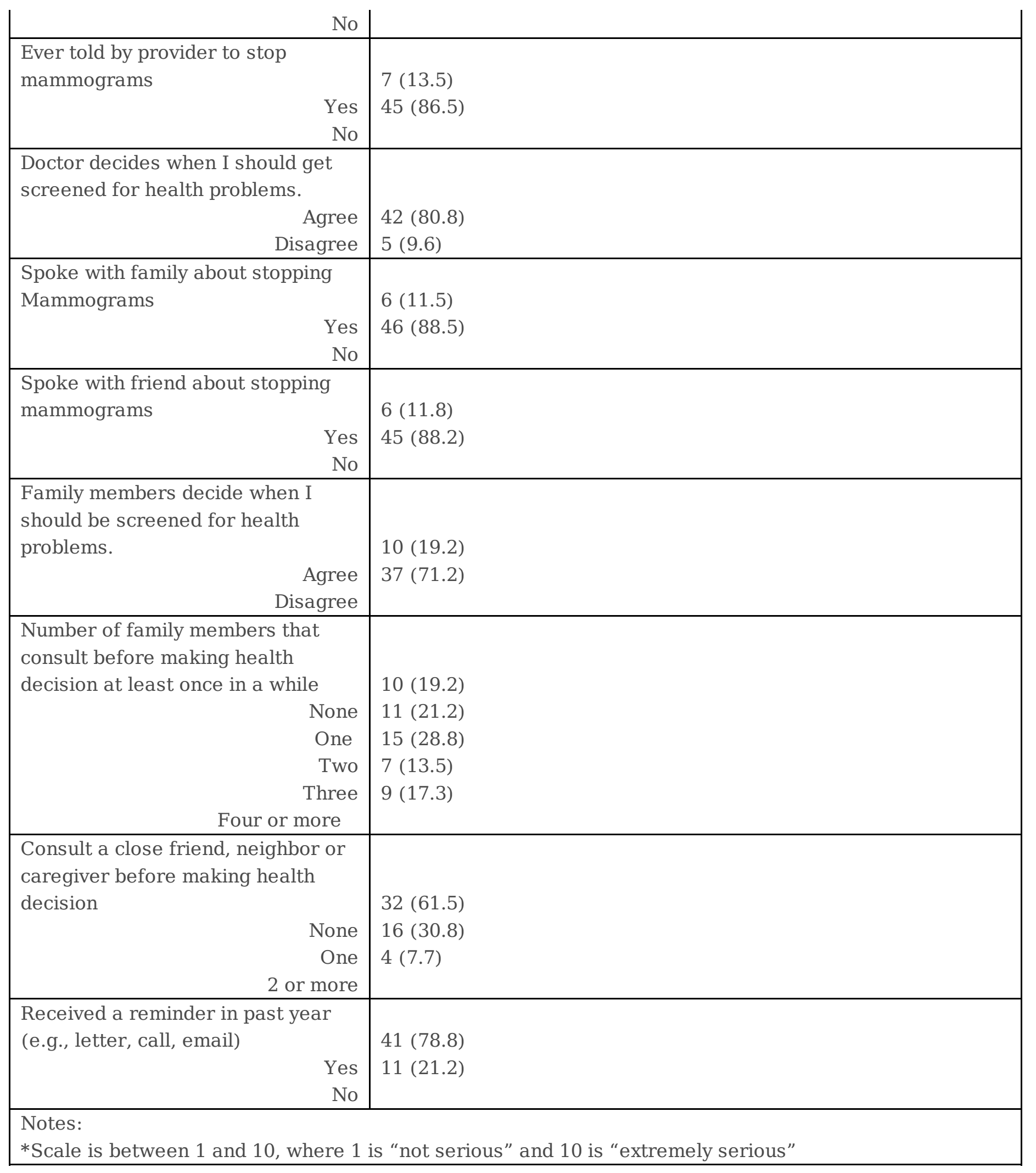

\section{Supplementary Files}

This is a list of supplementary files associated with this preprint. Click to download.

- TableSupplement.docx 